\title{
Evaluation of Spinal Anaesthesia Using Low Dose Hyperbaric Bupivacaine for Day-Care Surgery
}

\author{
Authors \\ Sanjeev Kumar ${ }^{1}$, ${ }^{*}$ Ravi Anand ${ }^{2}$, Chandrakant Prasad $^{3}$, Saurav Shekhar ${ }^{4}$, Kishore ${ }^{5}$, \\ K. H. Raghwendra ${ }^{6}$, Arun Kumar ${ }^{7}$ \\ ${ }^{1}$ Addl. Professor, Dept. of Anaesthesiology \& Critical Care Medicine, IGIMS, Patna, \\ ${ }^{2}$ Ex. Junior Resident, Dept. of Anaesthesiology \& Critical Care Medicine, IGIMS, Patna \\ ${ }^{3}$ Junior Resident, Dept. of Anaesthesiology \& Critical Care Medicine, IGIMS, Patna \\ ${ }^{4}$ Senior Resident, Dept. of Anaesthesiology \& Critical Care Medicine, IGIMS, Patna \\ ${ }^{5}$ Ex. Senior Resident, Dept. of Anaesthesiology \& Critical Care Medicine, IGIMS, Patna \\ ${ }^{6}$ Professor, Dept. of Anaesthesiology \& Critical Care Medicine, IGIMS, Patna \\ ${ }^{7}$ Ex.Professor \& Head, Dept. of Anaesthesiology \& Critical Care Medicine, IGIMS, Patna \\ *Corresponding Author \\ Dr Ravi Anand \\ Ex. Junior Resident, Dept. of Anaesthesiology \& Critical Care Medicine, IGIMS, Patna, India \\ Email:drravianand75@gmail.com
}

\begin{abstract}
Aim: To compare recovery time and evaluate home readiness time after different dosage of hyperbaric bupivacaine.

Material and Methods: This study was performed in 3 different groups: group-I, group-II \& group-III, each containing 50 patients. In study group-I, 6mg of hyperbaric bupivacaine, $8 \mathrm{mg}$ in hyperbaric bupivacaine in group-II and in study group-III $10 \mathrm{mg}$ hyperbaric bupivacaine was injected. The level of injection in all cases was at L2/3 vertebral interspace.

Results: In study group-I (6mg bupivacaine) failure rate was 6\%. Peri-operative complain of discomfort and pain was also high (12.76\%). Study group-Ill (10mg bupivacaine) did not show any advantage over group-II (8 $\mathrm{mg}$ bupivacaine). The 10mg dose prolonged the stay in PACU and delayed home-readiness by $44 \mathrm{~min}$ when compared with the $8 m g$ dose of spinal bupivacaine.

Conclusion: Standardized spinal anaesthesia technique with $8 \mathrm{mg}$ dose of hyperbaric bupivacaine produced a good quality highly predictable spinal block with average duration of 57 minutes stay in PACU and average home readiness time was 4.15 hours. Furthermore, a small change in dose on upper and lower side (6mg or $10 \mathrm{mg}$ ) altered the reliability, spread and recovery of the spinal anaesthesia.

Keywords: Hyperbaric Bupivacaine, Day-care surgery, Spinal anaesthesia.
\end{abstract}

\section{Introduction}

Any surgery in which patient is discharged from hospital on the same day of operation is called day care surgery ${ }^{1}$. Presently about $20 \%$ of surgical procedures in India are done as outpatient procedure. There are lots of benefits of day care surgeries such as less stay in hospital for the patients, fewer burdens on infrastructure of 
hospital, less economical burden and more satisfaction to patients. Different anaesthetic techniques as general anaesthesia, total intravenous anaesthesia (TIVA) and spinal anaesthesia are being used for day care surgery. Use of spinal anaesthesia in ambulatory settings is becoming more popular because this is simple and quick procedure which provides good surgical anaesthesia and results in rapid turnover of patient. Patients receiving spinal anaesthesia are more alert during recovery and incidence of nausea and vomiting is less than general anaesthesia. Patient may observe surgery and discuss options with the surgeon, immediate return to normal oral intake (particularly for patient with Diabetes), low post operative morbidity, high patient satisfaction, low venous thromboembolic phenomenon and delayed requirement of analgesics in postoperative period.

The most common drug used for spinal anaesthesia is hyperbaric bupivacaine in conventional dosage. Delayed recovery from sensory and motor block is common phenomenon leading to delayed discharge to home. Immediate intraoperative complications include bradycardia and hypotension. Post-operative complication includes postoperative nausea and vomiting (PONV), post dural puncture headache (PDPH), transient neurological symptoms (TNS), backache, and difficulty in voiding or urinary retention.

The purpose of our study was to evaluate reliable effect of spinal anaesthesia for day care surgery by using low dosage $(6 \mathrm{mg}, 8 \mathrm{mg}$ and10mg) of hyperbaric bupivacaine. Low dose of hyperbaric bupivacaine only affect the nerve root supplying a specific area. The specific aim was to compare the recovery time after different dosage of hyperbaric bupivacaine and furthermore, to evaluate the home readiness time after different dosage of hyperbaric bupivacaine.

\section{Material \& Methods}

After institutional ethical committee clearance and written informed consent, 150 patient of either sex belonging to ASA grade - I \& II aged between 2070 years and Body Mass Index (BMI) between 15$30 \mathrm{Kg} / \mathrm{m}^{2}$ posted for day care surgery were investigated in 3 separate study group. Patients were excluded if they had a history of coagulation disorders, psychiatric disorder, past history of allergy or adverse reaction to the local anaesthetics agents. Other exclusion criteria included history of pregnancy, any spinal deformity, infection at local site, BMI more than $30 \mathrm{~kg} / \mathrm{m}^{2}$, patient living far away from the hospital and any patient other than ASA grade I \& II. Study design was prospective, randomized double blind clinical study. A sea envelope technique, with computer generated numbers was used to randomize the patients. Study was performed in 3 different groups: group-I, group-II \& group-III each containing 50 patients. In study group-I $6 \mathrm{mg}$ of hyperbaric bupivacaine, $8 \mathrm{mg}$ in hyperbaric bupivacaine in group-II and in study group-III 10 $\mathrm{mg}$ in hyperbaric bupivacaine was injected, all at L2/3 vertebral interspace. After dural puncture and drug instillation, in all study group patient was tilted 5 degree head down for 6 minutes.

Patients were taken in OT with $18 \mathrm{G}$ intravenous line in-situ and after pre-medication with inj. Atropine $0.01 \mathrm{mg} / \mathrm{kg}$. All patients were preloaded with Ringer's lactate $15 \mathrm{ml} / \mathrm{kg}$. Multipara cardiac monitor was attached to patient and baseline NIBP, HR and $\mathrm{SpO}_{2}$ were recorded. Under strict aseptic precautions the study drug for respective group patient was loaded by an anesthesiologist not involved in the study. Therefore, the patient and the anesthesiologist performing the spinal block and recording the intraoperative and postoperative data were blinded. The study drug was injected into L2-L3 sub-arachnid space using 25G Quincke's spinal needle after confirming free and clear flow of cerebrospinal fluid and the time of injection was recorded as 0 minutes. Following this the patients were made to lie supine immediately. ECG and oxygen saturation was monitored continuously but reading of $\mathrm{SpO} 2$ was taken with pulse and NIBP which was monitored at every five minutes in first fifteen minutes then 
at every 15 minutes till the end of operation. Postoperatively, NIBP and $\mathrm{SpO}_{2}$ were monitored at every 30 minutes up to 2 hours from initial point. Patients were also observed for intra-operative bradycardia and hypotension which was managed with inj atropine and mephentramine respectively. Other complications like neurological symptoms, urinary retention, PDPH, PONV if any were also recorded.

\section{Statistical Analysis}

With power of study $80 \%$ and alpha error $5 \%$, the sample size came to 46 for each group. Considering drop outs, 50 patients were recruited in each group. SPSS for Windows 21 (SPSS, Chicago, IL, USA) was used for statistical analysis. Continuous variables were analyzed with the analysis of variance and categorical variables were analyzed with the Chi-Square Test and Fisher Exact Test. Statistical significance was taken as $\mathrm{P}<0.05$.

\section{Observation and Result}

All patients were divided in group-I, II \&III (Table.-1). Because of a failed block, three patients in group-I, one patient in group - II and one patient in group-III received GA for the surgical procedure and these patients were excluded from all analyses. One patient of study group-II was excluded from study due to failed dural puncture. Rest of the patients of group-I, II and III were included in the analysis of both sensory and motor block.

Table 1: Distribution of patients in study Group-I, II \& III

\begin{tabular}{|l|c|c|c|}
\hline & $\begin{array}{c}\text { Group } \\
\text { I }\end{array}$ & $\begin{array}{c}\text { Group } \\
\text { II }\end{array}$ & $\begin{array}{c}\text { Group } \\
\text { III }\end{array}$ \\
\hline Number of patients & 50 & 50 & 50 \\
\hline $\begin{array}{l}\text { Difficult/Impossible } \\
\text { dural puncture }\end{array}$ & 0 & 1 & 0 \\
\hline Total within group & 50 & 49 & 50 \\
\hline Failures & 03 & 01 & $01(2.0)$ \\
$(6.0)$ & $(2.04)$ & 49 \\
\hline Final within group & 47 & 48 & 49 \\
\hline
\end{tabular}

Clinic-demographic profiles of patients in all the groups were comparable as in table 2.
Table 2: Distribution of subjects on their characteristics in study groups

\begin{tabular}{|l|c|c|c|}
\hline & Group I & Group II & Group III \\
\hline $\begin{array}{l}\text { Number of } \\
\text { patient }\end{array}$ & 47 & 48 & 49 \\
\hline $\begin{array}{l}\text { Gender; } \\
\text { male/female }\end{array}$ & $36 / 11$ & $42 / 6$ & $37 / 12$ \\
\hline Age (year) & $44.2 \pm 15$ & $43.89 \pm 13.81$ & $42.12 \pm 13.67$ \\
\hline BMI(kg/m2) & $21.53 \pm 4.41$ & $21.51 \pm 4.53$ & $21.97 \pm 3.82$ \\
\hline $\begin{array}{l}\text { Duration of } \\
\text { surgery (min) }\end{array}$ & $27.74 \pm 14.65$ & $29.93 \pm 14.91$ & $27.85 \pm 16.64$ \\
\hline $\begin{array}{l}\text { Duration of } \\
\text { sensor } \\
\text { block(min) }\end{array}$ & $99.61 \pm 7.67$ & $119.97 \pm 3.81$ & $150.14 \pm 8.44$ \\
\hline $\begin{array}{l}\text { Duration of } \\
\text { motor } \\
\text { block(min) }\end{array}$ & $75.44 \pm 13.70$ & $94.34 \pm 8.70$ & $105.24 \pm 8.35$ \\
\hline
\end{tabular}

$B M I=$ body mass index $=$ Weight $\mathrm{Kg} /$ (height $\mathrm{m} 2$; value are mean $\pm S D$ or median

\section{Quality of the anaesthesia}

In all study group due to failure of spinal anaesthesia total 5 patients received GA and had to stay overnight in hospital, and were excluded from the study. The overall rate of failure was 3.3 $\%$ ( 5 patients) after SA. The final number of patients receiving successful spinal anesthesia was 47 in study group-I, 48 in study group-II and 49 in study group-III.

In study group-I, during intra operative period 6 (12.76\%) patient felt pain or discomfort. In study group III, during intra operative period only one (2.08\%) patient felt pain or discomfort. In study group-III, during intraoperative period no any (0\%) patient felt pain or discomfort. Those who felt pain or discomfort during Intraoperative period were treated with fentanyl $2 \mu \mathrm{g} / \mathrm{kg}$ intravenous.

The surgeon evaluated the quality of sensory block to be good or satisfactory in $87.2 \%$ and poor in $12.76 \%$ of patients after $6 \mathrm{mg}$ intrathecal hyperbaric bupivacaine (group-I) and the quality of sensory block to be good or satisfactory in $98 \%$ \& $100 \%$ of patient in study group-II \& III respectively. The surgeon evaluated the quality of motor block to be good or satisfactory in $86 \%$ of the patients after bupivacaine $6 \mathrm{mg}$ intrathecally. The quality of motor block was found to be poor in $14.8 \%$ of the patients after bupivacaine $6 \mathrm{mg}$ (study group-I). The quality of motor block to be good or satisfactory in $95.83 \%$ and $97.8 \%$ of the 
patients after bupivacaine $8 \mathrm{mg}$ and $10 \mathrm{mg}$ respectively (study group-II \& III). The quality of motor block to be poor in $14.8 \%, 4.17 \%$ and $2.2 \%$ of the patients after intrathecal bupivacaine $6 \mathrm{mg}$, $8 \mathrm{mg}$ and 10mg respectively (study group- I,II \&III).

In study group-I, 6mg hyperbaric bupivacaine injected at the L2/3 interspace and observed level of sensory block at $7 \mathrm{~min}$., $12 \mathrm{~min}$., 30min. at the end of surgery and every 20 min post operatively till complete recovery. On the operative side, the highest level of sensory block was seen at $30 \mathrm{~min}$ after the injection, reaching T10 level. The extension of sensory block decreased to L2 or lower after100min $(99.61 \pm 7.61)$.

In study group-III, all patients received $10 \mathrm{mg}$ of $5 \mathrm{mg} / \mathrm{ml}$ hyperbaric bupivacaine at L3/4 interspace and observed level of the sensory block at $7 \mathrm{~min}$., $12 \mathrm{~min} ., 30 \mathrm{~min}$. at the end of surgery and every 20 postoperatively till complete recovery. On the operative side, the highest level of sensory block was seen at $30 \mathrm{~min}$ after the injection, reaching T6 level. The extension of sensory block decreases to L2 or lower after $150 \mathrm{~min}(150.14 \pm 8.44)$.

To achieve an adequate level of sensory block $11(22 \%), 2(4 \%)$ and $1(2 \%)$ of the patients needed a modification of the posture (i.e.an additional head down tilt of the operation table for $3 \mathrm{~min}$ ), in the study group-I,II \& III respectively. After this change in posture, $6 \%$ and $2 \%$ of the patients Still had inadequate block for surgery (=failed block) in study group-I and II respectively. On the other hand, in study group-III when the higher dose $(10 \mathrm{mg})$ was injected at the L2/3 interspace with 5 degree head down of vertebral column, only $2 \%$ of patients needed additional head down tilt of operation table for 3 minutes and none of them produced successful sensory block ( $2 \%$ failed block).

Table 3: Showing level of sensory block after different time interval

\begin{tabular}{|l|c|c|c|}
\hline & Group-I & Group-II & Group-III \\
\hline Level at $7 \mathrm{~min}$ & L1 & Th12 & Th12 \\
\hline Level at 12 min & Th 12 & Th10 & Th10 \\
\hline Level at 30 min & Th 10 & Th 8 & Th6 \\
\hline $\begin{array}{l}\text { Block decreases to L2 } \\
\text { or lower level after }\end{array}$ & $100 \mathrm{~min}$ & $120 \mathrm{~min}$ & $150 \mathrm{~min}$ \\
\hline
\end{tabular}

Table 4: Distribution of effect of extra tilt of vertebral column

\begin{tabular}{|l|c|c|c|}
\hline & Group-I & Group-II & Group-III \\
\hline $\begin{array}{l}\text { Extra tilt for 3 } \\
\text { min needed }\end{array}$ & $11(22)$ & $2(4)$ & $1(2)$ \\
\hline $\begin{array}{l}\text { Successful } \\
\text { sensory block } \\
\text { after extra tilt }\end{array}$ & $8(16)$ & $1(2)$ & $0(0)$ \\
\hline $\begin{array}{l}\text { Failure sensory } \\
\text { block inspite }\end{array}$ & $3(6)$ & $1(2)$ & $1(2)$ \\
\hline
\end{tabular}

Values are $n(\%)$

Modified Bromage scale was used to evaluate motor block and recovery. The motor recovery was seen after $75.44 \mathrm{~min} \pm 13.70$ in group-I, 94.34 $\min \pm 8.70$ in group-II and $108.24 \mathrm{~min} \pm 8.35$ in group-III respectively.

The overall incidence of hypotension was $3.47 \%$ (5/144) and bradycardia was 9.02\% (13/144), after spinal anaesthesia (Table-5). In study group-I , none of the patient's in the spinal group needed treatment for hypotension verses $4.16 \%$ (2) patients in the group -II and 6.12\%(3) patient in group -III needed treatment for hypotension with Ephedrine $6 \mathrm{mg}$ iv $(\mathrm{p}=0.011)$. In study-I $4.16 \%$ (2), in group-II $10.4 \%$ (5) and in group-III 12.24 $\%$ (6) received treatment for bradycardia.

Table-5: Cardiovascular Side effects and their treatment

\begin{tabular}{|l|c|c|c|}
\hline & Group-I & Group-II & Group-III \\
\hline Hypotension & 0 & $2(4)$ & $3(6)$ \\
\hline Ephedrine & 0 & $2(4)$ & $3(6)$ \\
\hline Bradycardia & $2(4)$ & $5(10)$ & $6(12)$ \\
\hline Atropine & $2(4)$ & $5(10)$ & $6(12)$ \\
\hline
\end{tabular}

Values are in percentage (\%)

\section{Home readiness}

In study group-I, the standard home discharge criteria were fulfilled significantly faster after the use of $6 \mathrm{mg}$ of hyperbaric Bupivacaine compared to $8 \mathrm{mg}$ and $10 \mathrm{mg}$ dose of hyperbaric Bupivacaine. The home readiness time in mean \pm SD for study group-I was after $215.06 \pm 31.26 \mathrm{~min}$, for study group-II was after $254.37 \pm 29.98 \mathrm{~min}$. and study group-III was after $298.34 \pm 26.31 \mathrm{~min}$ ( $\mathrm{p}<0.001)$, respectively. 


\section{Complications at home}

The overall percentage of post dural puncture headache (PDPH) was 4.86 (7 patients out of 144). On the other hand $2.77 \%$ of the patients (4/144) developed transient neurological symptoms and $3.47 \%$ of the patients (5/144) developed backache after spinal anaesthesia. After spinal anaesthesia (in all study groups), $2 \%$ of the patients developed some difficulties in voiding, but none of them needed medical help.

\section{Discussion}

Neuraxial anaesthesia (i.e. spinal or epidural) is popular for day care surgery. Spinal anesthesia is easy to perform, rapid in onset ${ }^{2}$ and cheap ${ }^{3}$. In a study by Mulroy et al, the discharge times after EPI $(20 \mathrm{mg} / \mathrm{ml}$ chloroprocaine $)$ and GA (Propofol) were comparable, where as spinal anesthesia (procaine and fentanyl) was associated with a longer discharge time ${ }^{2}$.

An out-patient should be a carefully selected patient who is undergoing a non emergency procedure and all its constituent elements (admission, surgical procedure and discharge home) on the same day (Korttila 1995) ${ }^{5}$. An extended stay i.e. 23 hours or overnight should not be considered for day-care surgery ${ }^{1}$. Recovery can be divided into three phases: early, Intermediate and after recovery ${ }^{5}$. In the early stage of recovery, the patient emerges from anaesthesia and is usually looked after in the abundantly equipped and manned post anaesthesia care unit (PACU) or phase 1unit. Modem short acting drug in GA and techniques in RA have made the early stage recovery so that some patients can be safely fasttracked, i.e. by pass PACU (Apfelbaum et al. $2002)^{6}$.The ambulatory surgery unit (ASU) or phase II unit is a less expensive unit than the regular PACU; thus fast-tracking means savings in costs ${ }^{6}$. In most studies, the modified Aldrete scoring system has been used to determine fasttrack eligibility ${ }^{7,8}$. For patients undergoing UA, the new tast tracking criteria are more suitable, since they also take into consideration the common side effects, nausea and pain).During the stage of intermediate recovery, the patient achieves the criteria for home discharge. The discharge time (total recovery time) has been used as a measure of efficacy when comparing anaesthetic agents or techniques. However, several elements may cause confusion when comparing home-readiness. It has been demonstrated that many non-anaesthetic related factors had an effect on discharge time, postoperative nursing care being the single most important reason. A validated post anaesthesia discharge scoring system has been created by Chung and co-workers $(1995)^{9}$ based on stable vital signs, ability to walk, no or minimal pain, no or minimal postoperative nausea and vomiting, absence of severe bleeding, and ability to tolerate fluids.

During the past few years, the home discharge criteria have been changed. Mandatory drinking has been eliminated from the Practice Guidelines for Post-anaesthetic Care (The American Society of Anesthesiologists 2002) and, according to these guidelines, the routine requirement of voiding before discharge has also been recommended to be necessary only for selected patients (i.e, highrisk patients). After GA, local or peripheral nerve block, urinary retention affected $0.5 \%$ of the patients who were categorized as low-risk patients (non-pelvic surgery or outpatient gynaecological surgery), whereas in high-risk patients (hernia or anal surgery or a history of retention) the incidence was 5\%. The rate of re-retention after anal surgery was as high as 50\% (Pavlinet a1.1999).The patients should be informed to seek immediate medical help if any they are unable to void 6-8 hours after discharge (McGrath and Chung 2003) ${ }^{1}$.

In late recovery, the patient returns to the preoperative physiological state (Marshalland \& Chung 1999). Despite its subjective nature, patient satisfaction has been included in outcome studies. Overall satisfaction with low-dose spinal anaesthesia ranges from $92-99 \%$ of the patients (Kuusniemi et al. 2000a) ${ }^{10,11}$. 


\section{Conclusion}

In study group-I (6mg bupivacaine) failure rate was $6 \%$. Peri-operative complain of discomfort and pain was also high (12.76\%). Study group-Ill (10mg bupivacaine) did not show any advantage over group-II ( $8 \mathrm{mg}$ bupivacaine). The $10 \mathrm{mg}$ dose prolonged the stay in PACU and delayed homereadiness by $44 \mathrm{~min}$ when compared with the $8 \mathrm{mg}$ dose of spinal bupivacaine.

In conclusion, a standardized spinal anaesthesia technique with $8 \mathrm{mg}$ dose of hyperbaric bupivacaine produced a good quality highly predictable spinal block with Average duration of 57 minutes stay in PACU and average homeReadiness time was 4.15 hours. Furthermore, a small change in Dose on upper and lower side $(6 \mathrm{mg}$ or $10 \mathrm{mg}$ ) altered the reliability, spread and recovery of the spinal anaesthesia.

\section{References}

1. McGrath B, Chung F (2003) Postoperative recovery and discharge. Anesthesiology Clin North America 21:367-86

2. Mulroy MF (2002b) Spinal Anaesthesia. In Mulroy MF(ed) Regional Anesthesia: An illustrated procedure guide, $3^{\text {rd }}$ Edition. Lippincott Williams Wilkins, Philadelphia

3. Dahl V, Gierloff C, Omland E, Raeder JC (1997) Spinal, epidural propofol aesthesia for out-patient for knee arthroscopy? Acta Anaesthesiology Scand 41:1341-5

4. Heidvall $M$, Hein A, Davidson $S$, Jakobsson J (2000) Cost comparison between three different general anaesthetic techniques for elective arthroscopy of the knee. Acta Anaesthesiology Scand44 : 157-62

5. Korttila K. Recovery from outpatient anaesthesia: factors affecting outcome Anesthesia 1995;50 (Suppl): 22-8.

6. Apfelbaum JL, Walawander CA, Grasela $\mathrm{TH}$, et al. Eliminating intensive post operative care in same day-surgery patients using short acting anaesthetics. Anaesthesiology 2002; 97; 66-74.
7. Aldrete JA, Kroulick D (1970); A post anaesthetic recovery score. Anesth Analg 49: 924-34.

8. Aldrete JA (1995); The post-anaesthesia recovery score revisited. J Clin Anaesth 7:89-91

9. ChungF, Chan VW, Ong D (1995). A post-anesthetic discharge scoring system for home readiness after ambulatory surgery. JClinABath7:500-6.

10. Kuusniemi KS, Pihlajamiki KK, Kirveli OA, Korkeila JE (2001) Spinal anesthesia with hypobaric bupivacaine for knee arthroscopies: effect of posture on motor block. Reg Anath Pain Med 26:30-4

11. Kuusniemi KS, Pihlajamiki KK, Pitkinen MT, Korkeila JE (1999) low-dose bupivacaine: a comparison of hypobaric and near isobaric solutions for arthroscopic surgery of the knee. Anaesthesia 54:540-5 